Sādhanā Vol. 38, Part 1, February 2013, pp. 25-35. (c) Indian Academy of Sciences

\title{
Cavitation erosion resistance of 13/4 and 21-4-N steels
}

\author{
AKHILESH K CHAUHAN \\ Department of Mechanical Engineering, Kamla Nehru Institute \\ of Technology, Sultanpur 228118, India \\ e-mail: aknitpmt@ rediffmail.com
}

MS received 21 March 2010; revised 19 October 2011; accepted 2 April 2012

\begin{abstract}
Nitrogen strengthened austenitic stainless steel (termed as 21-4-N steel) in as cast and hot rolled conditions has been investigated as an alternative to $13 / 4$ steel (termed as CA6NM) to overcome the problems of cavitation erosion in hydro turbine underwater parts. The cavitation erosion of 21-4-N and 13/4 steels was investigated by means of an ultrasonic vibration processor. The cavitation erosion is highly dependent on microstructure and mechanical properties. The results show that hot rolled 21-4-N steel is more cavitation erosion resistant than the $13 / 4$ and $21-4-\mathrm{N}$ steels in as cast condition. The eroded surfaces were analysed through optical microscope and scanning electron microscope for study of erosion mechanisms.
\end{abstract}

Keywords. Martensitic stainless steel; nitrogen strengthened austenitic stainless steel; cavitation erosion; strain hardening; tensile toughness.

\section{Introduction}

Cavitation erosion is responsible for many machinery failures in the shipping and power generation industries. Cavitation erosion is a type of wear in systems in which a material comes into contact with a flowing liquid, e.g., hydro turbines, ship propellers etc. The bubble explode during cavitation generates very high and transient stresses (Karimi \& Martin 1986), which strains the materials in a particular way. For efficient operation of a hydro turbine, it must have specific shape and contour. Cavitation erosion leaves behind cavities or pits which affect these important contours, creating obstacles to smooth flow of water through the turbine. This leads to a loss of operating efficiency of the turbine. Considering the cost of electrical energy, even a relatively small change in the operating efficiency can be very expensive. Cavitation causes surface penetration damage of up to $10 \mathrm{~mm}$ per year to critical components such as impellors, turbine blades, and casings (Simoneau 1984). The end result is a reduction in energy extraction capacity that can lead to losses in terms of downtime, productivity, efficiency and money.

The martensitic chromium nickel stainless steel (13/4 or CA6NM steel) has wide application in hydro turbines, pumps and compressors. The erosion resistance of martensitic stainless steels can be attributed to the homogeneous distribution of deformation and the shorter effective mean 
free platelets of martensite (Karimi \& Martin 1986). It has been reported that the cavitationerosion-resistance is related to the degree of solution hardening of the matrix and the quantity, the structure, hardness, super-elasticity and super-plasticity (Heathcock et al 1982; Sang \& Li 1995; Huang et al 2002; Stoltz \& Vander 1980; Chauhan et al 2009). To overcome the problems of cavitation erosion, there is a need to develop a cavitation erosion resistant material for the fabrication of the underwater parts of hydro turbines. In an earlier paper (Chauhan et al 2009), the results on erosion by air-abrasive jets have been reported. In many critical applications, the net erosion loss is due to combined effect of erodent particles and cavitation. In this paper, the results on study of erosion due to cavitation alone has been reported. This paper deals with the cavitation erosion behaviour of $13 / 4$ and $21-4-\mathrm{N}$ steels investigated by means of ultrasonic vibration processor. The cavitation erosion behaviour of $13 / 4$ and $21-4-\mathrm{N}$ steels has been analysed as a function of microstructure, mechanical properties and alloying elements.

\section{Experimental procedures}

Experiments were conducted on 13/4 steel in as cast condition and 21-4-N steel in as cast and in hot rolled conditions. Long bars of $40 \times 40 \mathrm{~mm}$ cross section were received from M/S Star Wire (India) Ltd., Ballabhgarh (Haryana). The chemical compositions of these steels are given in table 1.

The cavitation erosion tests were conducted on as cast $13 / 4$ and $21-4-\mathrm{N}$ steels and hot rolled 21-4-N steel. The samples for cavitation erosion tests were cut by diamond cutter of $10 \times 10 \times$ $4 \mathrm{~mm}$ dimensions, ground and polished in order to obtain a surface free from scratches. Cavitation erosion resistance has been measured by means of an ultrasonic vibratory test. The ultrasonic vibratory test comprises of an electronic generator that generates 250 watt of average electrical energy. The transformer or velocity horn amplifies the small vibrations. It is attached to a pair of lead zirconate titanate transducer elements. This system uses a device to vibrate in the probe immersed in distilled water. The schematic of ultrasonic vibratory testing processor is given in figure 1 (Drozdz et al 2007). During half of each vibration cycle, a low pressure is created at the test specimen surface, producing cavitation bubbles. During the other half of the cycle, bubbles collapse at the specimen surface producing damage and erosion of the specimen. Although the mechanism for generating fluid cavitation in this method differs from that occurring in flowing systems and hydraulic machines, the nature of the material damage mechanism is believed to be basically similar. The method therefore offers a small scale, relatively simple and controllable test that can be used to compare the cavitation erosion resistance of different materials and to study the nature and progress of damage in a given material in detail. This standard test procedure for ultrasonic cavitation testing has been approved by the American Society for Testing and Materials (ASTM) as ASTM G32-06 (2007). The test specimen was placed at a small distance of $1 \mathrm{~mm}$ below the tip of the ultrasonic probe. The cavitation erosion was conducted for a total duration of $32 \mathrm{~h}$ each and weight loss was measured at every successive stage of $4 \mathrm{~h}$. The samples were cleaned in acetone, dried, weighed to an accuracy of $1 \times 10^{-4} \mathrm{~g}$ using an electronic

Table 1. Chemical composition of $13 / 4$ and $21-4-\mathrm{N}$ steels (wt \%).

\begin{tabular}{lcccccccccccc}
\hline Steel & $\mathrm{C}$ & $\mathrm{Si}$ & $\mathrm{Mn}$ & $\mathrm{Cr}$ & $\mathrm{Ni}$ & $\mathrm{N}$ & $\mathrm{S}$ & $\mathrm{Cu}$ & $\mathrm{Co}$ & $\mathrm{P}$ & $\mathrm{Mo}$ & $\mathrm{Fe}$ \\
\hline $13 / 4$ & 0.06 & 0.74 & 1.16 & 13.14 & 3.9 & - & 0.014 & .088 & 0.035 & 0.015 & 0.61 & $\mathrm{Bal}$ \\
$21-4-\mathrm{N}$ & 0.56 & 0.25 & 9.90 & 23.42 & 4.28 & 0.38 & 0.001 & 0.16 & 0.06 & 0.041 & - & $\mathrm{Bal}$ \\
\hline
\end{tabular}




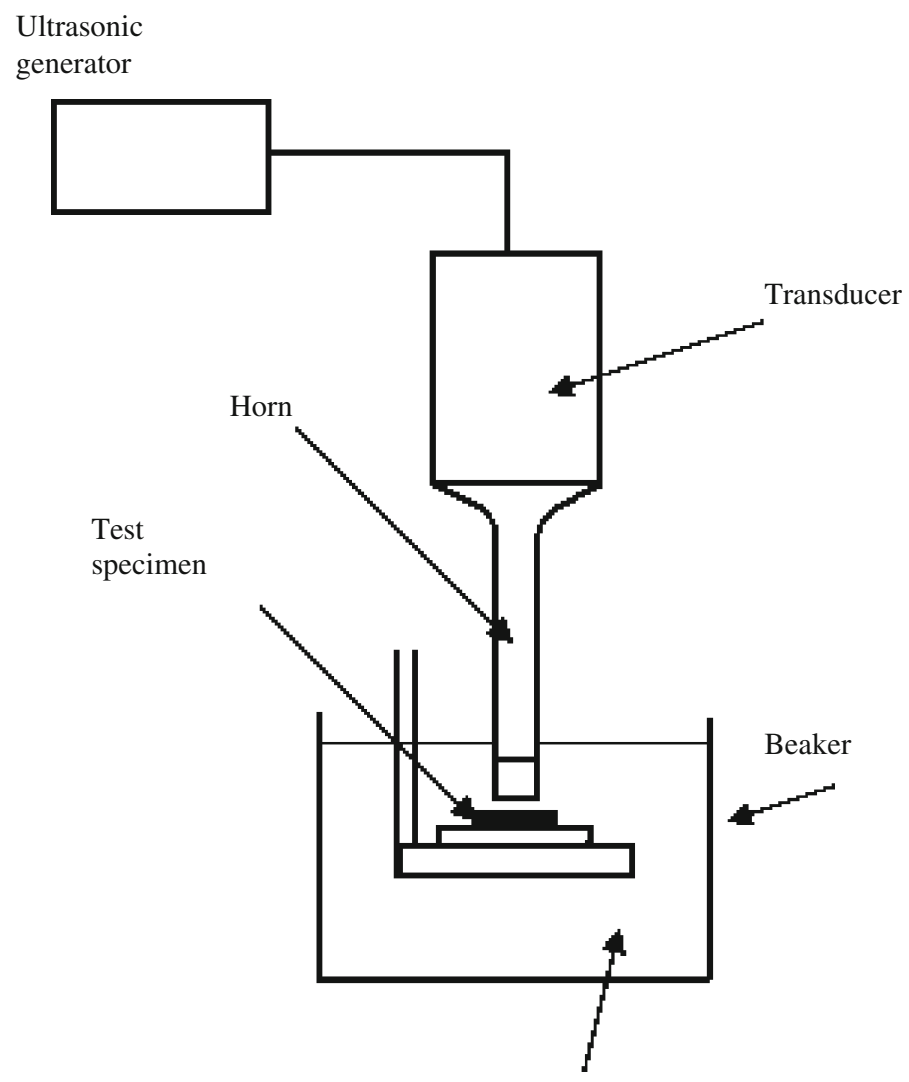

Test liquid

Figure 1. Schematic of the ultrasonic vibratory test device (Drozdz et al 2007).

balance, eroded in the ultrasonic vibratory processor for $4 \mathrm{~h}$ and then weighed again to determine weight loss. The eroded surfaces were studied on optical microscope and SEM to identify the mechanism of cavitation erosion. SEM study of eroded surfaces was conducted using FEI Quanta 2000 field emission scanning electron microscope (FESEM) at an accelerating voltage of $20 \mathrm{kV}$.

\section{Results and discussion}

\subsection{Microstructure and mechanical properties}

Figure 2 shows the microstructures of $13 / 4$ and $21-4-\mathrm{N}$ steels. The microstructure of as cast $13 / 4$ martensitic stainless steel consists of packets of very fine, untempered lath/martensitic needles (figure 2a). Apart from these packets, the structure exhibits a second phase, which is $\delta$ ferrite. The as cast 21-4-N steel, which is a nitrogen strengthened austenitic stainless steel having low $\mathrm{Ni}$ and higher concentration of $\mathrm{C}$, possesses predominantly austenitic phase along with the precipitates of carbides (figures $2 \mathrm{~b}$ and c). The carbides in 21-4-N steel are identified as $\mathrm{M}_{7} \mathrm{C}_{3}$ type, as reported in our earlier paper (Chauhan et al 2009), due to higher concentration of $\mathrm{N}$ and 


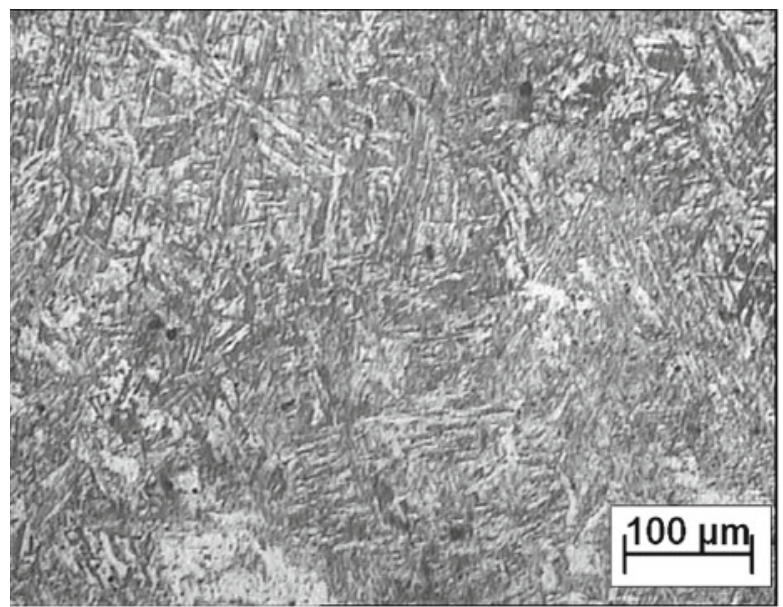

(a)

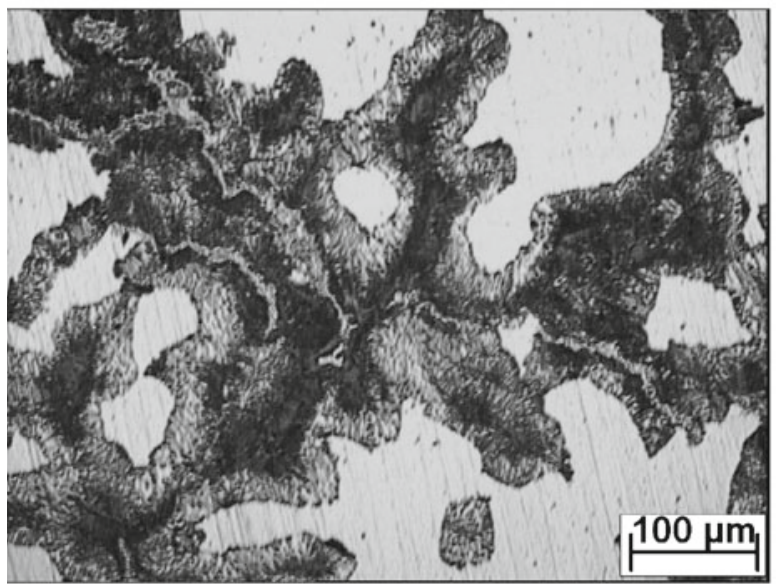

(b)

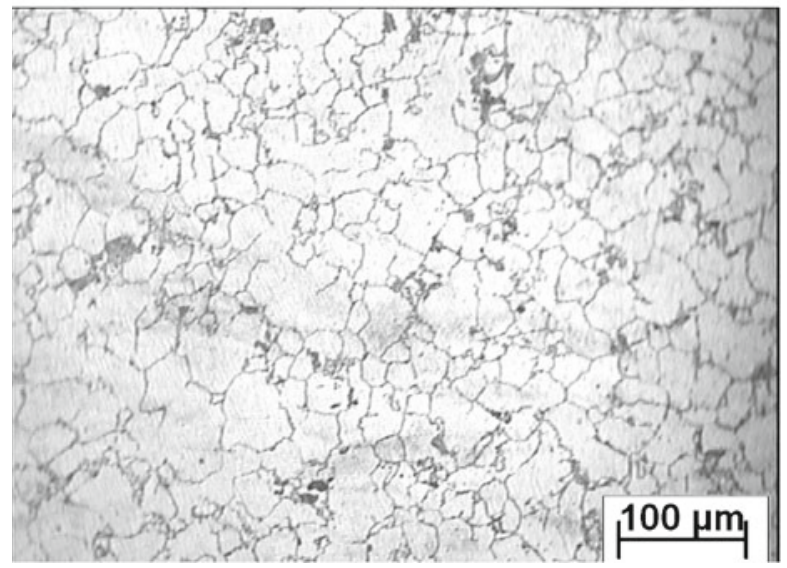

(c)

Figure 2. Microstructures of (a) as cast $13 / 4$ steel, (b) as cast 21-4-N steel and (c) hot rolled 21-4-N steel. 
Table 2. Mechanical properties of as cast $13 / 4$ steel and 21-4-N steel in as cast and hot rolled conditions.

\begin{tabular}{lccc}
\hline Properties & $\begin{array}{c}13 / 4 \text { Steel } \\
\text { As cast }\end{array}$ & $\begin{array}{c}21-4-\mathrm{N} \text { Steel } \\
\text { As cast }\end{array}$ & $\begin{array}{c}21-4-\mathrm{N} \text { steel } \\
\text { Hot rolled at } 1180^{\circ} \mathrm{C}\end{array}$ \\
\hline Hardness (VHN) & 305 & 320 & 339 \\
Impact energy (J) & 64 & 9 & 20 \\
YS (MPa) & 899 & 466 & 917 \\
UTS (Mpa) & 930 & 676 & 1207 \\
Ductility (\% elongation) & 14 & 17 & 29 \\
Tensile toughness (MJm & -3 & 73 & 254 \\
Strain hardening exponent $\left.^{-3}\right)$ & 68 & 0.46 & 0.57 \\
\hline
\end{tabular}

$\mathrm{C}: \mathrm{Cr}$ ratio. The mechanical properties of as cast $13 / 4$ steel and $21-4-\mathrm{N}$ steel in as cast and hot rolled conditions are given in table 2.

\subsection{Cavitation erosion behaviour}

The cumulative weight loss due to cavitation erosion for the samples in this investigation is plotted as function of time of cavitation erosion in figure 3, while figure 4 presents mean depth of erosion (MDE) versus time of erosion curve. MDE is calculated using equation (1). From figures 3 and 4 it is noticed that cumulative weight loss versus time of erosion curve and MDE as function of time of erosion curve are almost identical, because of the marginal difference in the densities of $13 / 4$ steel $\left(7.795 \mathrm{gcm}^{-3}\right)$ and $21-4-\mathrm{N}$ steel $\left(8.137 \mathrm{gcm}^{-3}\right)$, which is the only variable in the determination of MDE in this investigation. The erosion rate in as cast 13/4 steel is more than that in 21-4-N steel in both as cast and hot rolled conditions similar to solid particle erosion rate as described in our earlier paper (Chauhan et al 2009). However, the erosion resistance of 21-4-N steel in both as cast and hot rolled conditions in cavitation erosion is far better than that in solid particle erosion.

$\mathrm{MDE}=$ Erosion weight loss/density $\times$ cavitated area

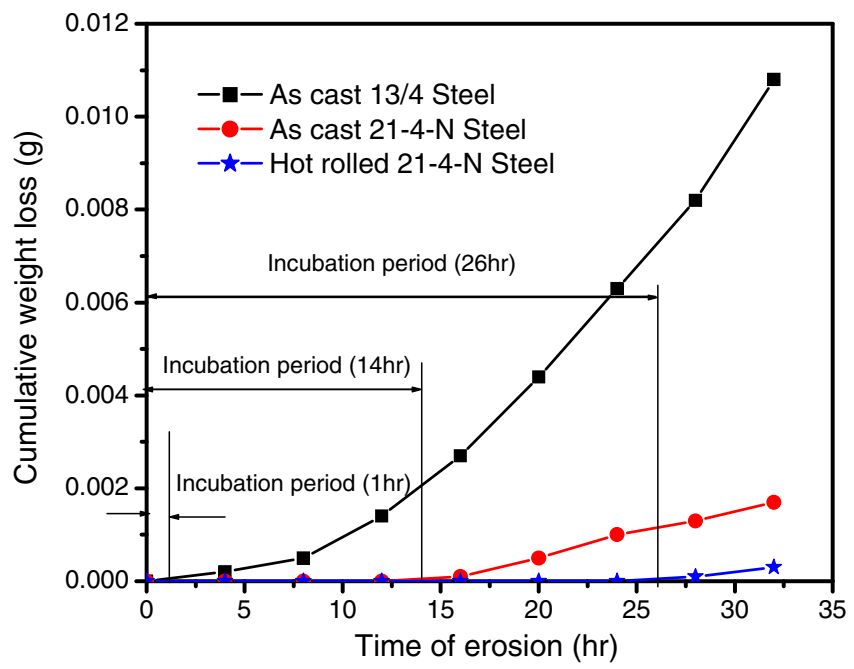

Figure 3. Cumulative weight loss as function of time of cavitation erosion. 


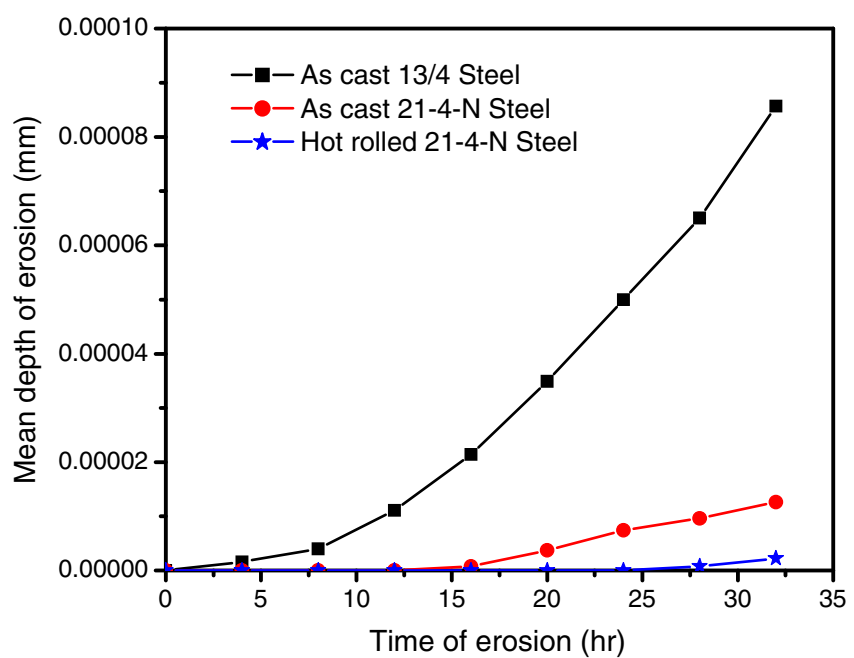

Figure 4. Mean depth of erosion (MDE) as function of time of cavitation erosion.

\subsection{Morphology of eroded surfaces}

Optical micrographs of the steels under investigation after different exposure of time during the test are shown in figures 5-7 and the SEM micrographs after $32 \mathrm{~h}$ of cavitation erosion test are

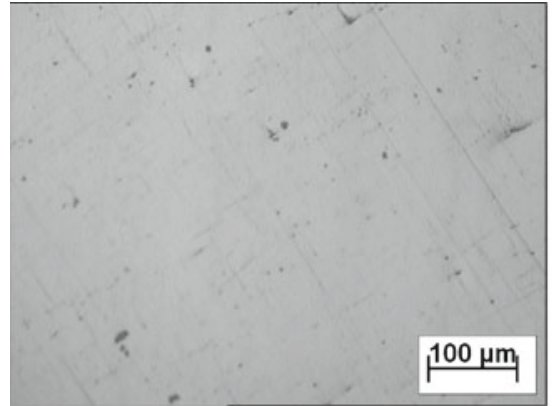

(a)

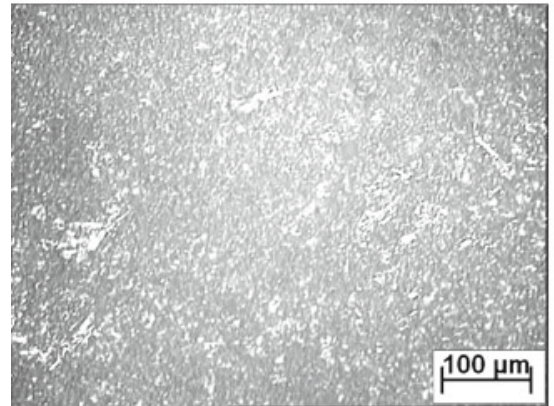

(c)

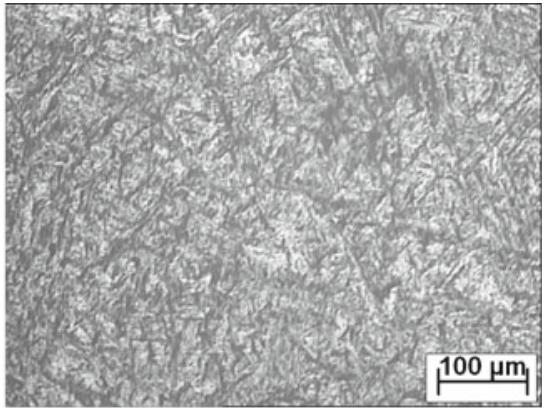

(b)

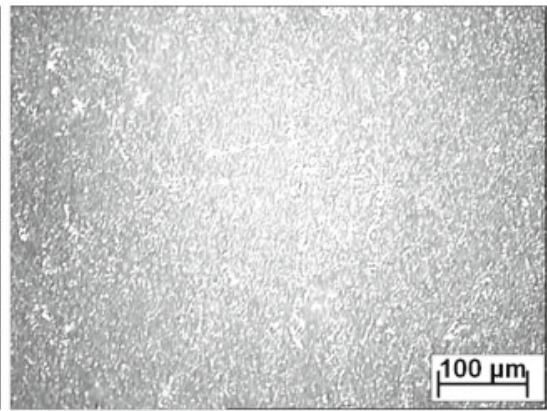

(d)

Figure 5. Optical micrographs of as cast $13 / 4$ steel (a) before cavitation erosion, (b) after $8 \mathrm{~h}$ of cavitation erosion, (c) after $16 \mathrm{~h}$ of cavitation erosion and (d) after $32 \mathrm{~h}$ of cavitation erosion. 


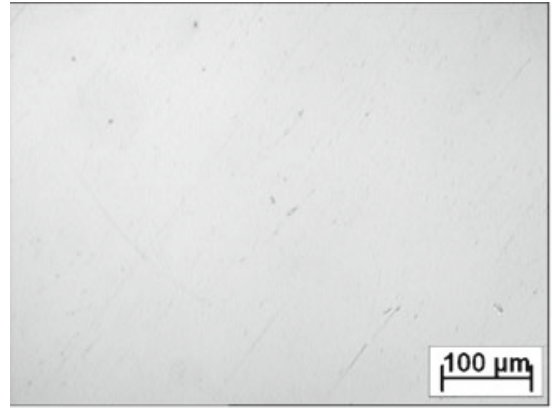

(a)

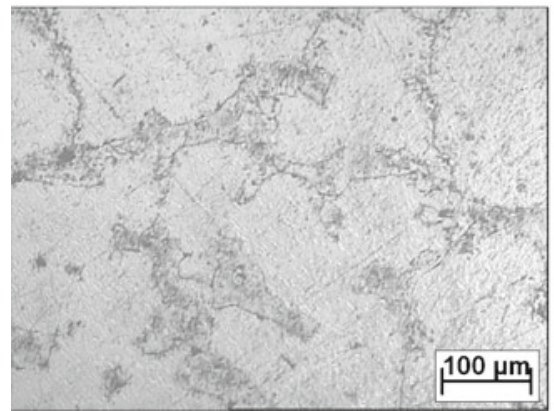

(c)

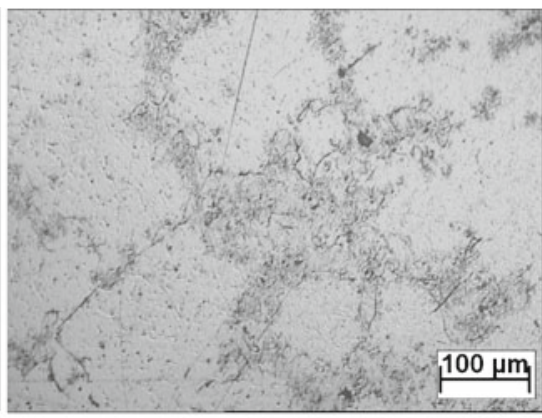

(b)

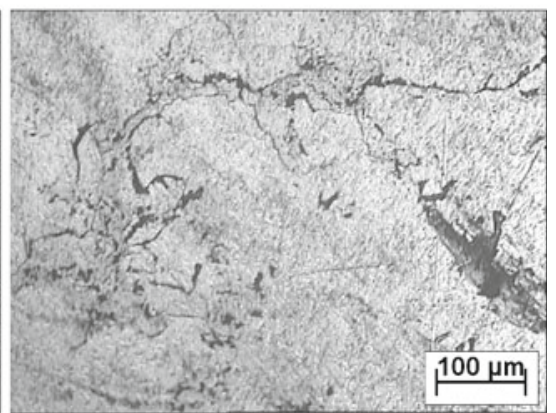

(d)

Figure 6. Optical micrographs of as cast 21-4-N steel (a) before cavitation erosion, (b) after $8 \mathrm{~h}$ of cavitation erosion, (c) after $16 \mathrm{~h}$ of cavitation erosion and (d) after $32 \mathrm{~h}$ of cavitation erosion.

shown in figure 8 . The material loss results presented in figure 3 and images obtained (figures 58) show a distinctive behaviour as a function of cavitation erosion time that can be divided in two stages: the first stage is characterized by an incubation period during which very little material loss is detected and the second stage represents a steady state erosion condition, where there is almost constant rate of material removal from the surface of the eroded specimen. The incubation time seems to be dependent on the microstructure as well as strain hardening ability of the alloys. The incubation time for hot rolled $21-4-\mathrm{N}$ steel is $26 \mathrm{~h}$, for as cast $21-4-\mathrm{N}$ steel is $14 \mathrm{~h}$ and for as cast $13 / 4$ steel it is $1 \mathrm{~h}$.

The micrographs shown in figure 5 are very similar to those reported by Liu et al (2003) for 0Cr13Ni5Mo stainless steel. In 13/4 steel the deformation due to cavitation attack is restrained in martensitic laths during initial stages of cavitation erosion (figure 5b). Since the material is removed from the surface of $13 / 4$ steel as cavitation erosion goes on, the martensitic laths are no more distinguished in a straight forward manner (figures $5 \mathrm{c}$ and $\mathrm{d}$ ).

Contrary to $13 / 4$ steel, the cavitation erosion morphologies of as cast $21-4-\mathrm{N}$ steel are different due to its austenitic structure. There is no obvious damage in the surface of as cast $21-4-\mathrm{N}$ steel after $8 \mathrm{~h}$ of cavitation erosion (figure 6). It can be seen that the damages develop mainly at austenite-carbide boundaries and this is a characteristic of cavitation, i.e., preferential attack on the weakest phase of a material. This observation is analogous with that of Okada et al (1983), in which it has been reported that the graphite inclusions provide the required crack initiation centers for rapid wear by brittle fracture. After $32 \mathrm{~h}$ of cavitation erosion in the as cast 21-4-N steel the cavities are formed due to material removal at austenite-carbide boundaries (figure $6 \mathrm{~d}$ ). 

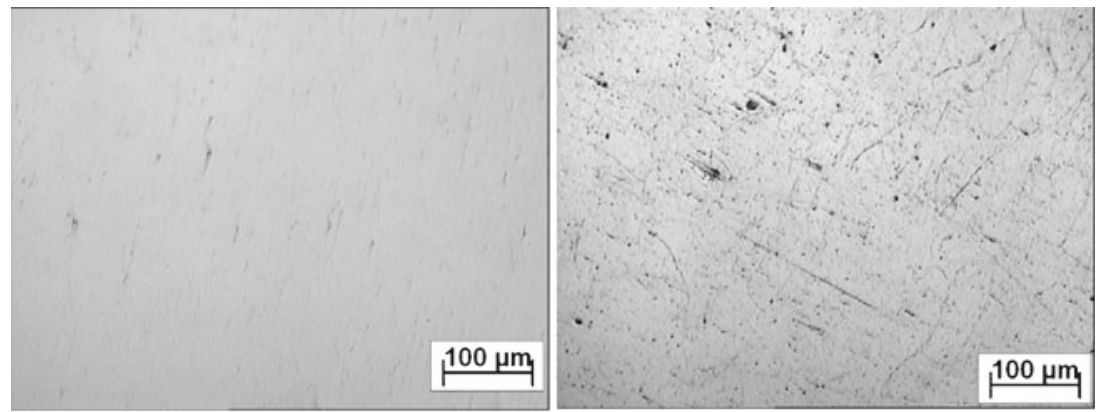

(a)

(b)

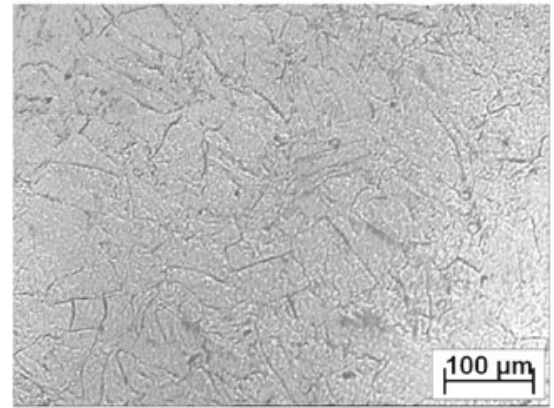

(c)

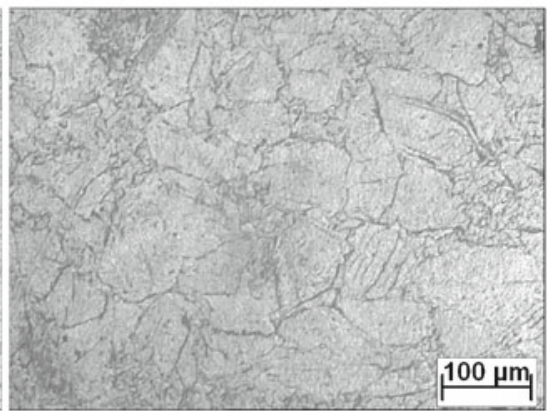

(d)

Figure 7. Optical micrographs of hot rolled $21-4-\mathrm{N}$ steel (a) before cavitation erosion, (b) after $8 \mathrm{~h}$ of cavitation erosion, (c) after $16 \mathrm{~h}$ of cavitation erosion and (d) after $32 \mathrm{~h}$ of cavitation erosion.

The cavitation erosion of hot rolled 21-4-N steel is different from that of the as cast condition due to its fine austenitic microstructure. This observation is similar to the observation reported by Garzon et al (2005). It has been reported that plastic deformation intensity in each grain is different due to both its own lattice spatial orientation and its neighbour's lattice spatial orientation. After $8 \mathrm{~h}$ of cavitation erosion, no obvious eroded marks are seen in the surface (figure 7b). After cavitation erosion of $16 \mathrm{~h}$, the grain boundaries become visible (figure 7c). This indicates that cavitation erosion occurs preferentially near carbide network located at grain boundaries. After $32 \mathrm{~h}$ of cavitation erosion also the damages are observed along the austenite grain boundaries (figure $7 \mathrm{~d}$ ).

Figure 8 shows the SEM micrographs of eroded surface of as cast 13/4 steel, as cast 21-4$\mathrm{N}$ steel and hot rolled 21-4-N steel, after $32 \mathrm{~h}$ of cavitation erosion test. The SEM micrograph of 13/4 steel, after $32 \mathrm{~h}$ of cavitation erosion (figure 8a), is similar to the result of Zhang et al (2007) for ZG06Cr13Ni5Mo. In this case, cavitation holes are formed during $32 \mathrm{~h}$ of cavitation erosion test and micro cracks are also observed. The SEM micrograph of eroded surface of as cast 21-4-N steel shows that the cavitation erosion starts along the interfaces between austenite and carbides (figure 8b). The cavitation holes are seen in the carbide regions. This may be due to the brittleness associated with carbides. The cavitation holes seen in the SEM micrograph of hot rolled 21-4-N steel may also be due to removal of carbide particles. The SEM micrographs of eroded surface of all the three specimens again suggest that higher erosion damage occurred in $13 / 4$ steel. 


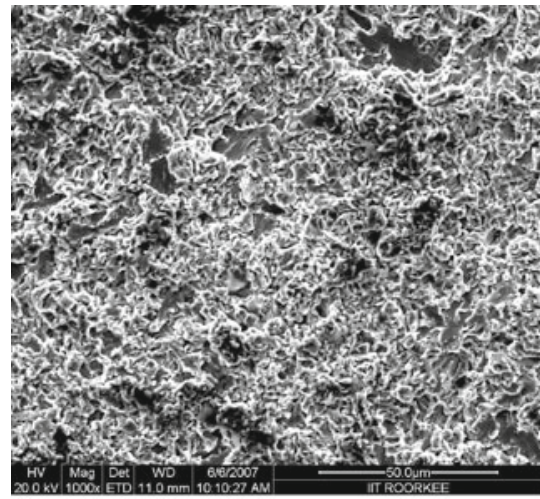

(a)

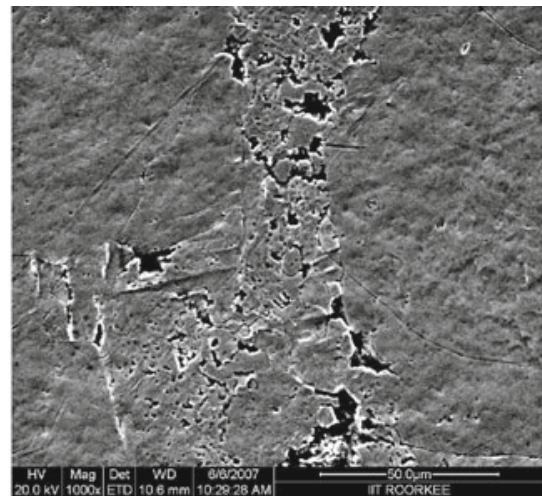

(b)

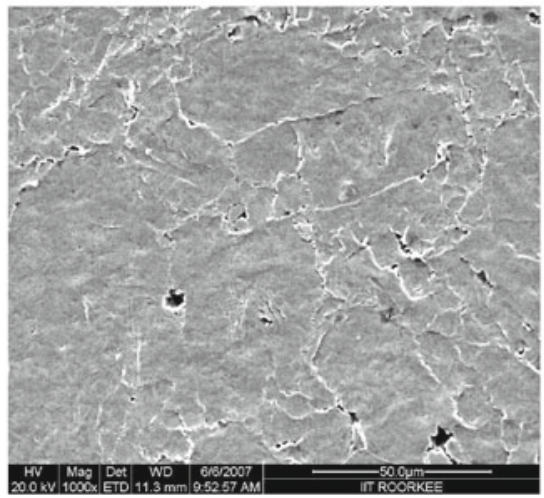

(c)

Figure 8. SEM micrographs of eroded surface of (a) $13 / 4$ steel, (b) as cast $21-4-\mathrm{N}$ steel and (c) hot rolled 21-4-N steel.

\subsection{Effect of microstructure on cavitation erosion}

The results of cavitation erosion test show that 21-4-N steel (as cast as well as hot rolled) because of its austenitic structure, gives more resistance against cavitation erosion in comparison to 13/4 martensitic stainless steel. During cavitation erosion, the target material is subjected to very high repeated loading by cavitation impact wave. The microstructure of target material plays a vital role in cavitation erosion. In 13/4 steel the martensitic structure, which is less likely to develop in situ strain hardening, and $\delta$-ferrite are the sources of cavitation attack. The austenitic matrix of 21-4-N steel, which is plastic and tough, is found to be beneficial parameters against cavitation erosion. Xi \& Zhou (1993) have reported in austenitic stainless steels, that the interface between carbide and austenite is associated with high stresses. As a result the interface between carbides and austenite is observed to be attacked severely in 21-4-N steel as compared to austenitic matrix. The interfaces are not able to undergo strain hardening and consequently become brittle and fragmented by cavitation attack; while the localized strength of austenite increases with strain hardening during cavitation erosion. Soussan \& Degallaix (1991) have also analysed that the localized strength of austenite in austenitic stainless steel increases with strain hardening. That is 
why, the austenite-carbide grain boundaries are attacked more in comparison to austenite grains of the as cast as well as hot rolled 21-4-N steel.

\subsection{Effect of mechanical properties on cavitation erosion}

Due to the repeated attack by cavitation impact wave, the target material undergoes deformation plastically. The hot rolled 21-4-N steel possesses higher ductility than the corresponding value for as cast 13/4 and 21-4-N steels. As a result, the former is able to sustain load for longer duration than the latter for given value of deformation. 13/4 Steel shows highest erosion damage (weight loss) of the three samples. The as cast 13/4 and 21-4-N steels having low ductility (14 and 17\%, respectively) show more erosion damage than that in hot rolled 21-4-N steel having higher ductility (29\%). Primarily, the hardness and ductility have been identified as main properties affecting erosion behaviour (Chauhan et al 2009). The hardness of the target material is detrimental to cavitation erosion resistance. Hot rolled 21-4-N steel possesses high hardness (339 VHN) as compared to as cast 21-4-N steel (320 VHN) and 13/4 steel (305 VHN) may erode rapidly, but cumulative effect of hardness and ductility results in less erosion damage. The high ductility and hardness of hot rolled $21-4-\mathrm{N}$ steel are responsible for more cavitation erosion resistance.

The cavitation erosion resistant materials should also absorb the energy of the cavitation impact wave, which delays the nucleation of cracks. The tensile toughness of a material is its ability to absorb energy in the plastic range. The tensile stresses induced in the material is not equivalent to the stresses developed in the tensile test described earlier since the strain rate is very high during cavitation erosion test. However, a correlation can be established from the cavitation erosion test results and tensile toughness. The values of tensile toughness are 68, 73 and $254 \mathrm{MJm}^{-3}$ as determined in earlier chapters from the area under their respective stress-strain curve between YS and fracture stress. It can be inferred that higher tensile toughness corresponds to more cavitation erosion resistance. The higher tensile toughness of hot rolled 21-4-N steel enables it to deform plastically due to repeated loading of cavitation attack and also absorbs more strain energy.

\subsection{Effect of strain hardening on cavitation erosion}

Steels with an austenitic matrix are more likely to develop in situ work hardening as compared to those with a martensitic structure. In this context, the stacking fault energy of the austenitic matrix plays an important role, as low stacking fault energy may cause a high rate of work hardening. Schramm \& Reed (1975) have reported that in Fe-Cr-Ni alloys Cr rapidly reduces the stacking fault energy. They have observed that $\mathrm{Ni}$ and $\mathrm{C}$ addition tend to increase the stacking fault energy while $\mathrm{Cr}, \mathrm{Si}, \mathrm{Mn}$ and $\mathrm{N}$ tend to decrease stacking fault energy in $\mathrm{Fe}-\mathrm{Cr}-\mathrm{Ni}$ austenitic alloys. The higher resistance to cavitation erosion in 21-4-N steel (as cast and hot rolled) can therefore, be attributed to the low stacking fault energy of its austenitic matrix.

From stress-strain diagram, it is noticed that severe in situ strain hardening occurs during tensile testing in both as cast and hot rolled 21-4-N steel, whereas less strain hardening takes place during tensile testing of $13 / 4$ steel. During cavitation erosion, high strain hardening exponent of 21-4-N steel corresponds to higher cavitation erosion resistance in comparison to $13 / 4$ steel possessing lower strain hardening exponent. From the SEM study of eroded surfaces (figure 8), it can be inferred that the martensitic laths of 13/4 steel embrittled earlier than austenite matrix in 21-4-N steel in both as cast and hot rolled conditions. The austenite matrix of 
21-4-N steel (figures 8b and c) deforms plastically and in situ strain hardening occurs, which delays the nucleation of cracks. This is in agreement with the results reported by Liu et al (2003). The austenite carbide boundaries of as cast 21-4-N steel are not able to undergo in situ strain hardening and become the sources of initiation of cracks. Therefore as-cast $21-4-\mathrm{N}$ steel is erode more in comparison to hot-rolled 21-4-N steel.

\section{Conclusions}

(i) The cavitation erosion resistance of $13 / 4$ steel investigated by means of ultrasonic vibration processor is less than that of 21-4-N steel in both as cast and hot rolled conditions. However, hot rolled 21-4-N steel exhibits excellent cavitation erosion resistance.

(ii) From the microstructure view point, the untempered martensitic laths of 13/4 steel erode more rapidly than the austenitic structure of $21-4-\mathrm{N}$ steel. The martensitic laths, already associated with internal stresses, are less able to absorb the strain energy due to transient stresses in the material induced by cavitation impact wave. It can also be inferred that the carbides present in 21-4-N steel are detrimental to cavitation erosion resistance leading to more erosion in as cast condition.

(iii) In 21-4-N steel in both as cast and hot rolled conditions, the cavitation erosion damages occur along the grain boundaries and the carbides are the first to be dislodged from the specimens.

(iv) In 21-4-N steel higher resistance to cavitation erosion is due to high hardness coupled with high ductility, high tensile toughness and high strain hardening exponent in comparison to those in $13 / 4$ steel.

\section{References}

Karimi A and Martin J L 1986 Int. Met. Rev. 31: 1

Simoneau R 1984 12th IAHR Symposium, Stirling, UK, 27

Heathcock C J, Protheroe B E and Ball A 1982 Wear 81: 311

Sang K and Li Y 1995 Wear 189: 20

Huang W H, Chen K C and He J L 2002 Wear 252: 459

Stoltz R E and Vander S J B 1980 Met. Trans 11A: 1033

Chauhan A K, Goel D B and Prakash S 2009 J. Alloys and Compounds 467(7): 459

Drozdz D, Wunderlich R K and Fecht H J 2007 Wear 262: 176

ASTM G32-06 2007 Standard test method for cavitation erosion using vibratory apparatus, West Conshohocken, PA

Liu W, Zheng Y G, Liu C S, Yao Z M and Ke W 2003 Wear 254: 713

Okada T, Iwai Y and Yamamoto A 1983 Wear 84: 297

Garzon C M, Thomas H, Santos J F and Tschiptschin A P 2005 Wear 259: 145

Zhang P, Jiang J, Ma A, Wang Z, Wu Y and Lin P 2007 Advanced Mat. Res. 15-17: 199

Xi Z T and Zhou Q D 1993 Wear 162-164: 83

Soussan A and Degallaix S 1991 Mat. Sci. Eng. A142: 169

Schramm R E and Reed R P 1975 Metall. Mat. Trans. A6A: 1345 